ББК 63.4

$$
\begin{gathered}
\text { Организация конференции и издание материалов проведены } \\
\text { при финансовой поддержке Российского фонда фундаментальных исследований, } \\
\text { проект № 19-09-20008 }
\end{gathered}
$$

Утверждено к печати Ученым советом ИИМК РАН

Редакционная коллегия тома II: А. В. Поляков, Е. С. Ткач (отв. редакторы), М. Т. Кашуба, Л. Б. Кирчо, Е. А. Черлёнок, В. Я. Стёганцева, А. И. Климушина

Рещензенты: д. и. н. Л. Б. Вишняцкий, д. и. н. А. А. Выборнов

Программный комитет конференции: академик РАН, д. и. н., проф. М. Б. Пиотровский (Государственный Эрмитаж, почетный председатель); д. и. н. В. А. Лапшин (ИИМК РАН, председатель); д. и. н. А. В. Головнёв (МАЭ РАН, сопредседатель); д. и. н. В. А. Дергачёв (Высшая антропологическая школа, Молдова, сопредседатель); д. и. н. И. Ф. Попова (ИВР РАН, сопредседатель); академик АН Республики Узбекистан, д. и. н., проф. Э. В. Ртвеладзе (сопредседатель); к. и. н. А. В. Поляков (ИИМК РАН, зам. председателя); к. и. н. В. А. Алёкшин (ИИМК РАН, зам. председателя); д. и. н. Ю. Е. Берёзкин (МАЭ РАН); Dr., Prof. Н. Бороффка

(Германский археологический институт, Германия); В. С. Бочкарёв (ИИМК РАН);

Dr. Э. Кайзер (Свободный университет Берлина, Германия); к. и. н. М. Т. Кашуба (ИИМК РАН); д. и. н. Л. Б. Кирчо (ИИМК РАН); к. и. н. А. В. Кияшко (Южный федеральный университет); к. и. н. П. Ф. Кузнецов (СГСПУ); к. и. н. Н. М. Малов (СНИГУ); к. и. н. В. П. Никоноров (ИИМК РАН); Ю. Ю. Пиотровский (Государственный Эрмитаж); д. и. н., проф. Д. Г. Савинов (Институт истории СПбГУ); к. и. н. В. Н. Седых (Институт истории СПбГУ); к. и. н. Н. Н. Скакун (ИИМК РАН); к. и. н. Н. Ф. Соловьёва (ИИМК РАН); к. и. н. А. И. Торгоев (Государственный Эрмитаж); к. и. н. Е. А. Черлёнок (Институт истории СПбГУ)

Организационный комитет конференции: к. и. н. А. В. Поляков (ИИМК РАН, председатель); к. и. н. В. А. Алёкшин (ИИМК РАН, зам. председателя); В. С. Бочкарёв (ИИМК РАН); к. и. н. М. Т. Кашуба (ИИМК РАН); д. и. н. Л. Б. Кирчо (ИИМК РАН);

А. И. Климушина (ИИМК РАН, отв. секретарь); к. и. н. В. П. Никоноров (ИИМК РАН); Ю. Ю. Пиотровский (Государственный Эрмитаж); В. Я. Стеганцева (ИИМК РАН); В. В. Терёхина (ИИМК РАН, МАЭ РАН, отв. секретарь); к. и. н. Е. С. Ткач (ИИМК РАН); И. Ж. Тутаева (Государственный Эрмитаж); к. и. н. Е. А. Черлёнок (Институт истории СПбГУ)

Древности Восточной Европы, Центральной Азии и Южной Сибири в контексте связей и взаимодействий в евразийском культурном пространстве (новые данные и концепции): Материалы Международной конференции, 18-22 ноября 2019 г., Санкт-Петербург. Т. ІІ. Связи, контакты и взаимодействия древних культур Северной Евразии и цивилизаций Востока в эпоху палеометалла (IV-I тыс. до н. э.). К 80-летию со дня рождения выдающегося археолога В. С. Бочкарёва. - СПб.: ИИМК РАН, Невская Типография, 2019. - 287 с.

ISBN 978-5-907053-35-9

DOI 10.31600/978-5-907053-35-9 
of the Eastern Mediterranean 9. Wien. P. 473-478 (Österreichische Akademie der Wissenschaften, Denkschriften der Gesamtakademie. 37).

Pavúc P. 2014. Troia VI Früh und Mitte. Keramik, Stratigraphe, Chronologie. Studia Troica. Mon. 3. Bonn.

Pavúc P., Pieniążek M. 2016. Towards Understanding the Socio-Political Structures and Social Inequalities in Western Anatolia during the Late Bronze Age. In: Arm und Reich - Zur Ressourcenverteilung in prähistorischen Gesellschaften. Halle. P. 531-551 (Tagungsband des Landesmuseums für Vorgeschichte Halle. 14).

Pavúc P., Pieniążek M., Riehl S. 2014. Troy and the Troad in the Second Millennium: Changing Patterns in Landscape Use. In: Physis l'environnement naturel et la relation home-milieu dans le monde Égéen Protohistorique. Leuven; Liege. P. 111-120 (Aegaeum. 37).

Pieniążek M. 2016. A Polity in Transition: Troy in the $2^{\text {nd }}$ Millennium BC. In: Von Baden bis Troia; Ressourcennutzung, Metallurgie und Wissenstransfer. Leidorf. P. 513-534.

Soroceanu T. 2011. "Gadius barbarico ritu humi figitur nudus". Schriftliches, Bildliches und Ethnologisches zur Bedeutung der Schwerter und der Schwertdeponierungen au. erhalb des militarischen Verwendungsbereiches In: Tyragetia. S.n. Vol. 5 (20), nr. 1. S. 39-116.

Van de Moortel A., Zahou E. 2012. Five years of archaeological excavation at the Bronze Age and

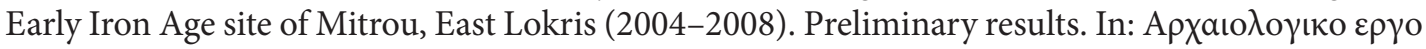

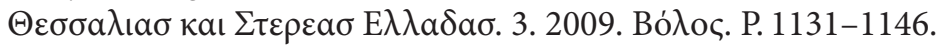

Zidarov P. 2006. Alltagsleben in Zeiten von Krieg und Frieden - Bronzezeitliche Artefakte aus Knochen und Elfenbein. In: Troia. Archäologie eines Siedlungshügels und seiner Landschaft. Mainz. S. 227-230.

\title{
CHEEK-PIECES OF THE WATER HORSES (ONE OF THE MYTHOLOGEMS IN CULTURES OF EURASIA OF THE BRONZE AGE)
}

Vyacheslav A. Podobed, Anatoliy N. Usachuk, Vitaliy V. Tsimidanov

Donetsk Regional Museum of Local History, Donetsk, Ukraine

Keywords: Troy, cheek-pieces, earthquakes, Poseidon, horses, rituals.

The present paper discusses the two fragmentary rod-shaped cheek-pieces from antler found in the course of excavations of the Citadel of Troy VI (square E8). On the basis of consideration of other finds, the conclusion is drawn that the area of square E8 can have been used for practicing ritual manipulations. It is of interest that these cheek-pieces are the first details of horse bridle of the Bronze Age discovered in Troy. The authors suppose that residents of Troy who suffered from earthquakes practiced rituals against wrath of a god, an analogue of Poseidon, and the key role in these rituals was played by horses. It is possible that the cheek-pieces found in square E8 were a consequence of exactly such a rite.

\section{ТИГЛИ И СОПЛА ИЗ ПОГРЕБЕНИЙ «КУЗНЕЦОВ-ЛИТЕЙЩИКОВ» РАННЕГО И СРЕДНЕГО БРОНЗОВОГО ВЕКА ВОСТОЧНОЙ ЕВРОПЫ}

\author{
А. В. Батасова \\ Независимый исследователь, Санкт-Петербург, Россия
}

DOI: $10.31600 / 978-5-907053-35-9-47-51$

Ключевые слова: Восточная Европа, эпоха бронзы, древнее металлопроизводство, погребения «кузнеи,ов-литейщиков», литейный инвентарь.

На территории Восточной Европы известно более 40 погребений «кузнецов-литейщиков». Для этих комплексов характерно наличие специализированного инвентаря — литейных форм, тиглей, сопел, а также кузнечных инструментов. В работе предпринята попытка 
систематизации тиглей и сопел из 31 погребения (табл. 1), относящихся к позднему энеолиту - финалу среднего бронзового века.

Таблица 1

Погребения «кузнецов-литейщиков» с тиглями и соплами раннего и среднего бронзового века Восточной Европы

\begin{tabular}{|c|c|}
\hline Комплекс & Публикация материалов \\
\hline Вареновка 4/5 & Ильюков 1986: 229, рис. 4, 1 \\
\hline Васильевка 1/20 & Kaiser, Plešivenko 2000: 139, рис. 9, 2, 3, 5, 6 \\
\hline Верхняя Криница 4/7 & Березанская, Ляшко 1989: 25, рис. 4 \\
\hline Верхняя Маёвка XII 2/10 & Ковалева 1979: 113, рис. 16, 1 \\
\hline Волосовско-Даниловский могильник, погр. 20 & Крайнов 1971: 16, рис. 3, 3 \\
\hline Ворошиловград (Луганский сельхозинститут) 3/16 & Березанская 1980: 250, рис. 3, 5, 6, 8 \\
\hline Воскресенка $3 / 3$ & Кубышев, Нечитайло 1991: 12, рис. 4, 2 \\
\hline Громовка $1 / 7$ & Кубышев, Нечитайло 1991: 8, рис. 2, 4-6 \\
\hline Жутово $1 / 3$ & Шилов 1966: 90, рис. 39, 1-3 \\
\hline Каиры 1/11 & Černych 2003: 45, рис. 9, 12, 13 \\
\hline Калиновка $1 / 4$ & Кубышев, Нечитайло 1991: 12, рис. 4, 5 \\
\hline Калиновский могильник 55/13 & Шилов 1959: 15, рис. 2, 4, 5 \\
\hline Калиновский могильник 8/42 & Шилов 1959: 17-18, рис. 5, 6-9; 6, 2, 3 \\
\hline Каменка 2/7 & Кубышев, Нечитайло 1991: 8, рис. 2, 2 \\
\hline Копани II $1 / 1$ & Берестнев 2001: 209, рис. 50, 4 \\
\hline Краматорск (разрушенное погребение) & $\begin{array}{l}\text { Шапошникова 1971: 24, рис. 2; Березанская, } \\
\text { Кравец 1989: 164, рис. 3, } 2\end{array}$ \\
\hline Красновка 36/20 & Тощев 2007: 134, рис. 71, 3, 4 \\
\hline Лакедемоновка I 1/12 & Ильюков 1986: 228, рис. 3, 1 \\
\hline Лакедемоновка III 1/4 & Ильюков 1986: 228, рис. 3, 2 \\
\hline Лебеди I 3/10 & Гей 1986: 20, рис. 6 \\
\hline Лосево 3/5 & Матвеев, Маслихова 2004: 91, рис. 7, 5 \\
\hline Малая Терновка 2.7. & Кубышев, Черняков 1985: 44, рис. 6, 1-8 \\
\hline Новоалексеевка 1/6 & Березанская, Кравец 1989: 161, рис. 2, 5, 6 \\
\hline Павловка 27/20 & Клюшинцев 1991: 258, рис. 3, 7, 8 \\
\hline Павловский 38/3 & Синюк 1983: 74, рис. 29, 12 \\
\hline Пепкинский курган, погр. 1, скелет 8 & Халиков и др. 1966: 66, 68, рис. 8; 10 \\
\hline Покровка 4/3 & Березанская, Кравец 1989: 158, рис. 1, 16-19 \\
\hline Пришиб 1/9 & Братченко 2001: 35, рис. 32, 2 \\
\hline Стыла $1 / 12$ & Березанская, Кравец 1989: 165, рис. 4, 4 \\
\hline Калиновка (разрушенное погребение) & Цуцкин 1982: 95, рис. 2: 14, 15 \\
\hline Шахтерск 2/5 & Березанская, Кравец 1989: 165, рис. 4, 5 \\
\hline
\end{tabular}

Тигли (32 экз.) различной конструкции найдены в 22 комплексах. В основу их классификации положены морфологические признаки: форма чаши, наличие или отсутствие держателя и слива, оформление держателя и слива. Особое место в классификационной схеме занимают тигли из Пепкинского кургана. Все они имеют ножку - приспособление для удерживания, по всей видимости. Прочие тигли можно разделить на несколько групп и подгрупп. 
Группа 1. Тигли без держателя.

Группа 1.1. С полусферическими чашами. Комплексы: Верхняя Маёвка XII 2/1010 , Волосовско-Даниловский могильник, погр. 20, Лебеди I 3/10.

Группа 1.2. С уплощенно полусферическими чашами. Комплексы: Лакедемоновка I 1/12, Лакедемоновка III 1/4; Вареновка 4/5, Стыла 1/12, Шахтерск 2/5.

Группа 1.3. С чашами вытянутых скорлуповидных и подтреугольных очертаний. Комплексы: Воскресенка 3/3, Каиры 1/11, Ворошиловград (Луганский сельхозинститут) 3/16, Краматорск (разрушенное погребение).

Группа 2. Тигли с держателем.

Группа 2.1. С плоским выступом, перпендикулярно сливу. Комплексы: Красновка 36/20, Малая Терновка 2/7, Васильевка 1/20, Громовка 1/7, Верхняя Криница 4/7, Калиновский могильник 8/42.

Группа 2.2. С выступом-втулкой. Комплексы: Павловский могильник 38/3, Копани II 1/1.

Особый случай представляет собой тигель из погребения Покровка 4/3. Он сделан из профилированной стенки сосуда и имеет выступ, функция которого неясна.

Таким образом, за исключением тиглей из Пепкинского кургана и Покровки 4/3, все остальные тигли разделены нами на две группы и пять подгрупп. Необходимо отметить, что тигли первой группы (без держателей) в целом имеют большие размеры чаши по сравнению с тиглями второй группы (с держателями) (рис. 1, 1), что может быть обусловлено ограничениями конструкции тигля с выступом-ручкой, при которой удерживание чаши большого диаметра затруднительно.

Сопла (32 экз.) встречены в 17 погребениях. В основу их классификации положены размеры (высота, диаметр основания) и устройство канала. На основании этих признаков можно выделить следующие группы и подгруппы сопел.

Группа 1. Сопла без уступов.

Группа 1.1. Удлиненные с узким основанием. Комплексы: Калиновский могильник 55/13, Новоалексеевка 1/6, Лосево 3/5, Калиновский могильник 8/42.

Группа 1.2. Средней длины с широким основанием. Комплексы: Павловка 27/20.

Группа 1.3. Укороченные, с основанием средней ширины. Комплексы: Красновка 36/20, Малая Терновка 2/7, Калиновский могильник 8/42.

Группа 2. Сопла с уступом.

Группа 2.1. Удлиненные с широким основанием. Комплексы: Покровка 4/3, Калиновка 8/42, Калиновка (разрушенное погребение).

Группа 2.2. Укороченные с широким основанием. Комплексы: Васильевка 1/20, Громовка 1/7, Каменка 2/7, Калиновка 1,4, Покровка 4,3.

Группа 2.3. Короткие на узком основании. Комплексы: Жутово 1/3.

Единично сопло из погребения Воскресенка $3 / 3$, имеющее сильно сглаженный уступ. В ходе систематизации нами было выделено две группы и шесть подгрупп сопел. Важно отметить корреляцию между конструкцией канала и пропорциями сопел. Так, большинство сопел с уступом короче сопел без уступов (рис. 1,2). Наличие уступа или резкое сужение канала обеспечивает более резкий перепад давления, и, следовательно, большую мощность воздушной струи. В случае с постепенно сужающимся каналом для увеличения разности диаметров входного и выходного отверстия и усиления воздушной струи требуется удлинение сопла.

\footnotetext{
${ }^{1}$ Первым указывается название могильника, затем номер кургана и номер погребения, то есть Верхняя Маёвка XII 2/10 означает: могильник Верхняя Маёвка XII, курган 2, погребение 10; слово «могильник» опускается.
} 

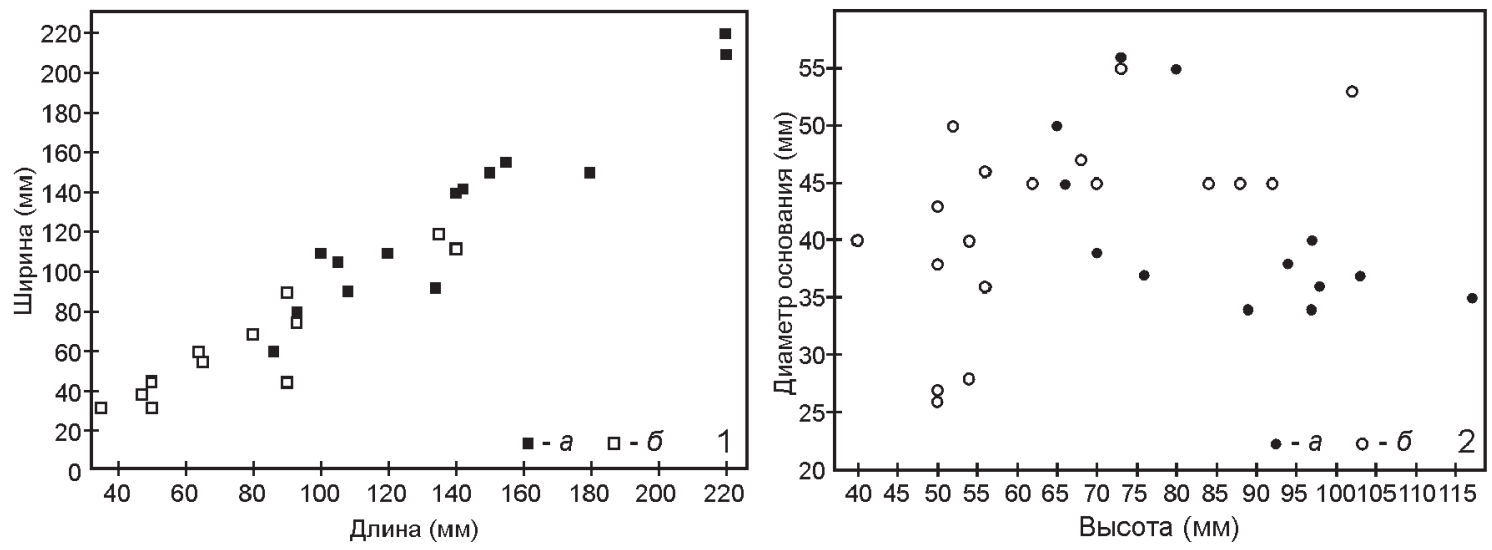

Рис. 1. Диаграммы размеров тиглей и сопел из погребений «кузнецов-литейщиков» раннего и среднего бронзового века Восточной Европы: 1 - тигли ( $a-6 е з$ держателя, группа 1 ; $\sigma-$ с держателем, группа 2$) ; 2-$ сопла $(a-$ без уступов, группа $1 ; 6-$ с уступами, группа 2$)$

Результаты проведенного анализа демонстрируют широкое разнообразие форм тиглей и сопел, встреченных в погребениях «кузнецов-литейщиков», а также важное технологическое значение их конструкций, которая может быть связана с уровнем развития технологии металлопроизводства.

\section{Литература}

Березанская С.С. 1980. Первые мастера-металлурги на территории Украины // Артёменко И. И. (отв. ред.). Первобытная археология - поиски и находки: Сб. науч. тр. Киев. С. 243-256.

Березанская С. С., Кравец Д. П. 1989. О металлургическом ремесле племен Донецкой катакомбной культуры // Березанская С. С. (отв. ред.). Первобытная археология. Материалы и исследования: Сб. науч. тр. Киев. С. 156-168.

Березанська С. С., Ляшко С. М. 1989. Вивчення ремесла за виробничими комплексами 3 пам’яток доби бронзи // Археологія. № 3. С. 18-30.

Берестнев С. И. 2001. Восточноукраинская лесостепь в эпоху средней и поздней бронзы (ІІ тыс. до н. э.). Харьков.

Братченко С. Н. 2001. Донецка катакомбна культура раннього етапу. Ч. 1. Луганськ.

Ильюков Л. С. 1986. Погребения литейщиков эпохи средней бронзы из северо-восточного Приазовья // СА. № 2. С. 226-231.

Клюшинцев В.Н. 1991. Погребение литейщика на реке Ингулец // Братченко С.Н. (отв. ред.). Катакомбные культуры Северного Причерноморья. Источники, проблемы, исследования: Сб. науч. тр. Киев. С. 254-261.

Ковалева И. Ф. 1979. Вытянутые погребения Днепровского ареала Волго-Днепровской культурно-исторической общности эпохи энеолита // Ковалева И. Ф. (отв. ред.). Курганные древности степного Поднепровья (III-I тыс. до н. э.): Сб. науч. тр. Днепропетровск. Вып. 3. С. 61-70.

Крайнов Д.А. 1971. Металлургия у племен фатьяновской культуры // КСИА. Вып. 127. С. 10-17.

Кубышев А. И., Черняков И. Т. 1985. К проблеме существования весовой системы у племен бронзового века степей Восточной Европы (на материалах погребения литейщика катакомбной культуры) // СА. № 1. С. 39-54. 
Кубышев А. И., Нечитайло А. Л. 1991. Центры металлообрабатывающего производства Азово-Черноморской зоны // Братченко С. Н. (отв. ред.). Катакомбные культуры Северного Причерноморья. Источники, проблемы, исследования: Сб. науч. тр. Киев. С. 6-21.

Матвеев Ю. П., Маслихова Л. И. 2004. Курганная группа «Таганка» // Синюк А. Т. (отв. ред.). Археологические памятники бассейна Дона: Межвуз. сб. науч. тр. Воронеж. С. 87-97.

Синюк А. Т. 1983. Курганы эпохи бронзы Среднего Дона (Павловский могильник). Воронеж.

Тощев Г. Н. 2007. Крым в эпоху бронзы. Запорожье.

Гей А. Н. 1986. Погребение литейщика новотиторовской культуры из Нижнего Прикубанья // Каменецкий И. С. (отв. ред.). Археологические открытия на новостройках. Вып. 1: Древности Северного Кавказа. М. С. 19-32.

Халиков А. Х., Лебединская Г. В., Герасимова М. М. 1966. Пепкинский курган. Йошкар-Ола. Цуцкин Е. В. 1982. К истории металлообработки срубных племен // Эрдниев У.Э. (ред.). Памятники Калмыкии каменного и бронзового веков. Элиста. С. 93-99.

Шапошникова О. Г. 1971. До питання про металлообработку у племен донецької катакомбної культури // Археологія. № 1. С. 22-26.

Шилов В. П. 1959. Калиновский курганный могильник // Памятники Нижнего Поволжья. С. 323-523 (МИА. № 60).

Шилов В. П. 1966. Погребение литейщика катакомбной культуры в Нижнем Поволжье // КСИА. Вып. 106. С. 88-91.

Černych L. 2003. Spektralanalyse und Metallverarbeitung in den früh- und mittelbronzezeitlichen Kulturen der ukrainischen Steppe als Forschungsproblem. In: Eurasia Antiqua. Nr. 9. S. 27-62.

Kaiser E., Plešivenko A. 2000. Die bronzezeitlichen Grabsitten im unteren Dnieprgebiet. In: Eurasia Antiqua. Nr. 6. S. 125-208.

\section{CRUCIBLES AND NOZZLES FROM BURIALS OF “SMITHS-CASTERS” OF THE EARLY AND MIDDLE BRONZE AGE}

\section{Anzhela V. Batasova}

Independent researcher, Saint Petersburg, Russia

Keywords: burials of "smiths-casters", Bronze Age of Eastern Europe, early metallurgy, casting implements.

This study is an attempt at systemizing crucibles and nozzles from 31 burials of 'smiths-casters'. Into the basis of classification of the crucibles, their morphological features were laid: shape of the bowl, the presence or absence of a holder and of an outlet, and their form. Two groups and five subgroups of crucibles have been distinguished. Crucibles of the first group (without holders) have the bowl of a larger size than crucibles of the second group (with holders) (Fig. 1, 1). This feature was possibly due to the limitations on the construction of a crucible with a ledge where it was difficult to hold a bowl of a large diameter.

The classification of the nozzles is based on the dimensions (height, diameter of the base) and construction of the pipe. In the course of systematization, two groups and six subgroups of nozzles were distinguished. A tendency has been noted that the nozzles with ledges are shorter than those without (Fig. 1, 2). This was related to the necessity to increase the difference of size between the input and output orifice and enhancement of the air jet. In the shortened nozzles this task is solved owing to the ledges or a sharp narrowing of the pipe. 